LA-UR- $10-0 / 629$

Approved for public release; distribution is unlimited.
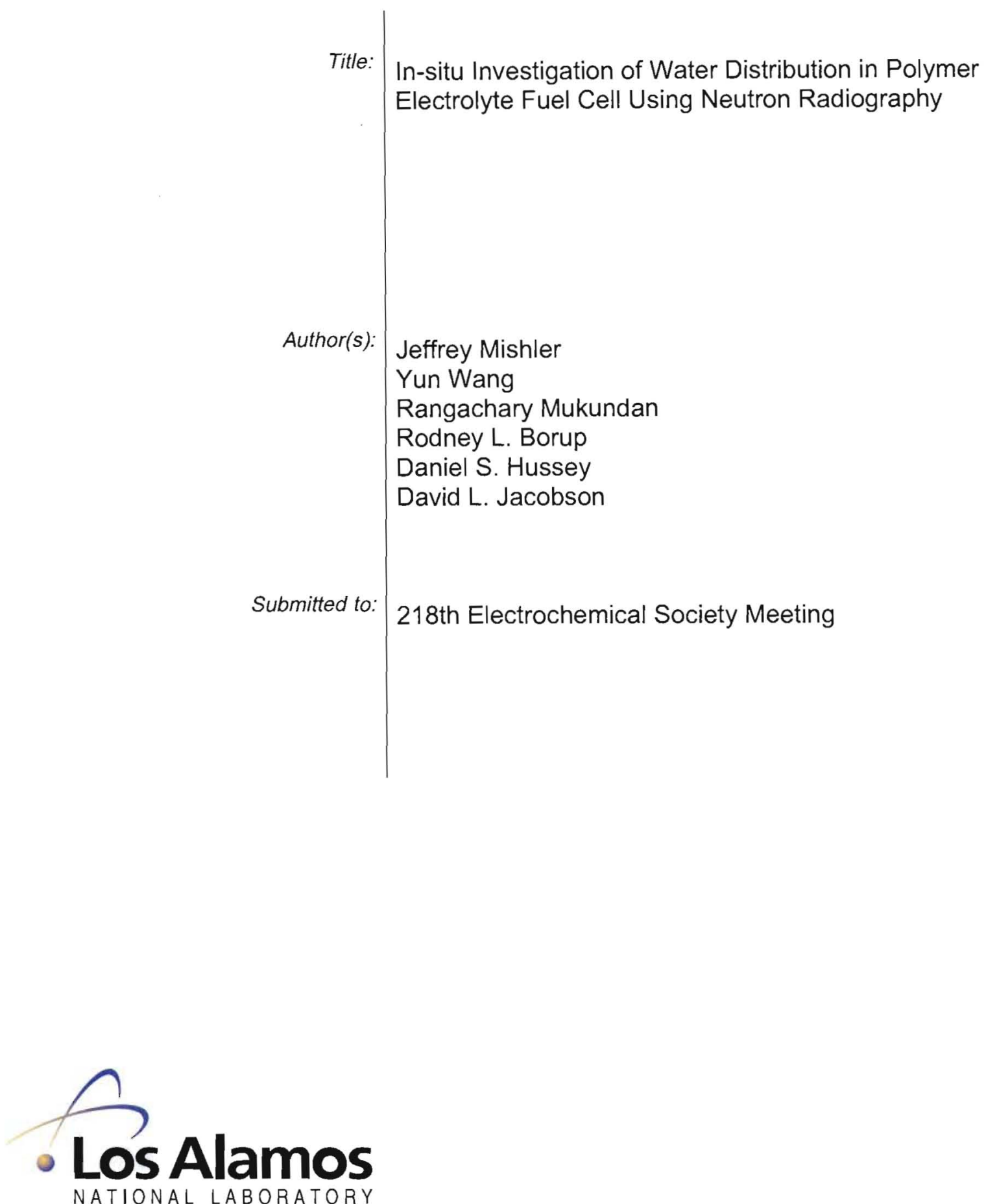

Los Alamos National Laboratory, an affirmative action/equal opportunity employer, is operated by the University of California for the U.S. Department of Energy under contract W-7405-ENG-36. By acceptance of this article, the publisher recognizes that the U.S. Government retains a nonexclusive, royalty-free license to publish or reproduce the published form of this contribution, or to allow others to do so, for U.S. Government purposes. Los Alamos National Laboratory requests that the publisher identify this article as work performed under the auspices of the U.S. Department of Energy. Los Alamos National Laboratory strongly supports academic freedom and a researcher's right to publish; as an institution, however, the Laboratory does not endorse the viewpoint of a publication or guarantee its technical correctness. 


\title{
In-situ Investigation of Water Distribution in Polymer Electrolyte Fuel Cell Using Neutron Radiography
}

\author{
Jeffrey Mishler ${ }^{a}$, Yun Wang ${ }^{a *}$, Rangachary Mukundan ${ }^{b}$, Rodney Borup ${ }^{b}$, Daniel S. \\ Hussey $^{\mathrm{c}}$, David L. Jacobson ${ }^{\mathrm{c}}$ \\ ${ }^{a}$ Renewable Energy Resources Lab, Department of Mechanical and Aerospace \\ Engineering, \\ The University of California, Irvine, 92697-3975, USA \\ ${ }^{\mathrm{b}}$ Los Alamos National Laboratory (LANL), MS D429, MPA-11, Los Alamos, NM 87545, \\ USA \\ ${ }^{c}$ National Institute of Standards and Technology (NIST), Center for Neutron Research, \\ 100 Bureau Drive, MS 8461, Gaithersburg, MD 20899, USA
}

This paper investigates the water content within operating polymer electrolyte membrane (PEM) fuel cells using neutron radiography. We consider fuel cells with various PTFE loadings in their gas diffusion layers (GDL) and microporous layers (MPL), and examine the impacts of MPL/GDL properties on the liquid water behavior and fuel cell performance. Fuel cells are tested at both dry and fully hydrated conditions with different serpentine flow fields. Water contents in the projected areas of channel and land regions are probed. The fuel cell may be subject to more flooding at low current-density operation. Both MPL and GDL wetting properties have substantial impacts on the water content in fuel cell. Cell performance also varies on different scenarios of the MPL/GDL wetting properties. A quad-serpentine channel flow field exhibits higher water content without remarkable change in performance at low current densities. Liquid water profile along the channel is presented and on-set clearly indicated.

\section{Introduction}

Polymer electrolyte membrane (PEM) fuel cells for automotive applications will likely operate with inlet gas streams at less than saturated conditions. With relatively dry gas flows it is important to fully understand the water management within the fuel cell in order to ensure membrane hydration to reduce the ohmic polarization.

Liquid water may exist in an operating PEM fuel cell (1) even at low humidity operation (2). During operation, different GDLs show various liquid distributions (3). The addition of a microporous layer (MPL) to the gas diffusion layer (GDL) has been shown to increases the catalyst utilization and improve fuel cell water management (4). Weber et al. (5) developed an analytical model to examine the effect of wettability of the diffusion media on water management, and demonstrated that owing to its higher hydrophobicity and lower porosity the MPL is less susceptible to water flooding than the carbon substrate, and also proposed that the MPL acts as a valve that pushes water away from the GDL to the flow field to minimize water flooding (6). The PTFE serves as a 
binder to maintain the integrity of carbon particles in the MPL, and provides high hydrophobicity to avoid water flooding. However, the optimized value of PTFE has been shown in the literature to vary by condition from $10 \%(7), 15 \%(8), 20 \%(9)$, and $30 \%$ on substrate and $15 \%$ on the MPL (10). Park (11) used water permeation experiments to indicate that PTFE increases the resistance of the water flow through the GDL due to a decrease of the MPL porosity and an increase of the volume fraction of hydrophobic pores, and performance showed that the optimized PTFE loading of $23 \%$ had effective water management. Wood (12) tested the effect of PTFE loadings in the GDL by use of a segmented cell to show in-plane performance differences.

By utilizing neutron imaging we are able to quantify the water content and distribution in a running fuel cell. Analysis of the response to current step-up and stepdown for different PTFE loadings in the GDL was presented by Davey et al. (13). This study presents experimental results and analysis of the effect of different PTFE weight loadings on the water content inside a fuel cell and its performance. We consider both dry and fully hydrated conditions and a wide range of operating current densities.

\section{Experimental}

\section{Fuel Cell Steady-State Testing}

The fuel cell hardware was designed at LANL specifically for neutron imaging, employing gold-plated aluminum. Two different flow field designs were tested, either single serpentine or quad-serpentine. The MEA used was a Gore ${ }^{\mathrm{TM}}$ Primea $($ MEA Series

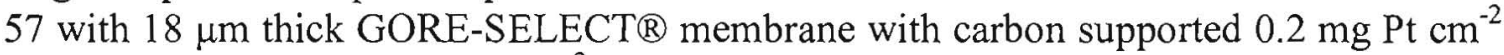

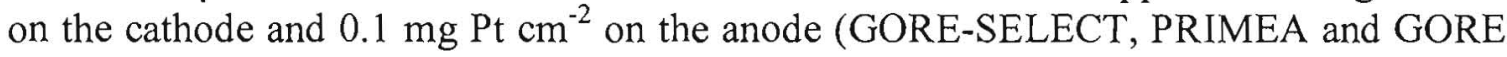
are trademarks of W. L . Gore \& Associates, Inc). The GDLs used were SGL Carbon's carbon paper 24-Series with a $200 \mu \mathrm{m}$ thick substrate and a $50 \mu \mathrm{m}$ thick MPL. The cells differed in the channel flow field patterns and in the PTFE weightings, as described in Table I.

Table I. Properties of tested fuel cells.

\begin{tabular}{cccccc}
$\begin{array}{c}\text { Cell } \\
\text { Number }\end{array}$ & Flow Field Type & $\begin{array}{c}\text { Anode } \\
\text { Substrate }\end{array}$ & $\begin{array}{c}\text { PTFE Loading (weight \%) } \\
\text { Anode } \\
\text { MPL }\end{array}$ & $\begin{array}{c}\text { Cathode } \\
\text { Substrate }\end{array}$ & $\begin{array}{c}\text { Cathode } \\
\text { MPL }\end{array}$ \\
\hline 1 & Single Serpentine & $5 \%$ & $23 \%$ & $20 \%$ & $10 \%$ \\
2 & Single Serpentine & $5 \%$ & $23 \%$ & $5 \%$ & $23 \%$ \\
4 & Single Serpentine & $5 \%$ & $5 \%$ & $20 \%$ & $10 \%$ \\
5 & Quad Serpentine & $5 \%$ & $23 \%$ & $20 \%$ & $10 \%$ \\
\hline
\end{tabular}

The fuel cells were operated at $80^{\circ} \mathrm{C}$. Anode hydrogen and cathode air stoichiometries of 1.2 and 2.0 respectively, and with minimum anode and cathode flows of 50 and 75 standard $\mathrm{cm}^{3} \mathrm{~min}^{-1}$. The inlet relative humidity of the gas streams was set at $0 \%, 50 \%$, and $100 \%$ for the anode and cathode sides. Most measurements were performed in a co-flow configuration, with some additional measurements made in counter-flow operation. The outlet gas backpressure was $172 \mathrm{kPa}$ absolute.

Steady state operation tests were carried out at constant current, with the current density varied from 0 to $1.6 \mathrm{~A} / \mathrm{cm}^{2}$ in intervals of $0.4 \mathrm{~A} / \mathrm{cm}^{2}\left(0,0.4,0.8,1.2,1.6 \mathrm{~A} / \mathrm{cm}^{2}\right)$. This was achieved by setting the fuel cell to a certain current density, and then waiting 
for at least 15 minutes for a steady state to be reached. Measurements were taken for at least 30 minutes.

The effects of the humidity of the inlet gases, hydrogen on the anode side and air on the cathode side, on the water density within the operating fuel cell was monitored. For the steady state tests, relative humidity for the steady state conditions was either $50 \%$ anode $/ 50 \%$ cathode or $100 \%$ anode $/ 100 \%$ cathode.

\section{Neutron Imaging}

Neutron imaging was performed at the NIST Center for Neutron Research (NCNR) on thermal beam tube 2. The sensor used for imaging had a pixel dimension of $127 \mu \mathrm{m} \times$ $127 \mu \mathrm{m}$.

Neutron image analysis was performed using the IDL programming language, a dry reference image, and an additional reference image to correlate water thickness to imaging response, as described by Hickner et al. (14).

Masks were made to represent the lands, channels and active area of the cells. For the pixels at the boundaries between the channel and land areas it cannot be said what percent of the detected water is from the channel and what percent is in the land. We have chosen to not include these pixels as either land or channel. This means that the channel and land masks cover the middle $(\sim 80 \%)$ of the channel and land area, respectively. The active area mask includes the area under the channel, lands, and the above-mentioned area between the channel and land.

The masks were further broken down into segments to determine the along-channel distribution of water in the fuel cells. The single-serpentine flow field was segmented into 7 parts.

Each fuel cell was imaged for one-second, and the 60 exposures for each minute then averaged into a single image. For each operating condition at least 301 -minute intervals were imaged, and then averaged to get the average steady state water content of the cell.

\section{Results and Discussion}

\section{PTFE loading in the anode and cathode GDL}

The water content of the land and channel area in each of the three single-serpentine cells is shown in Figure 1 below. 
Land: 50/50RH

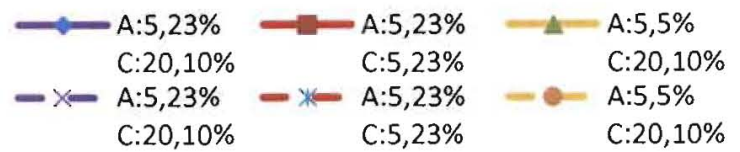

Channel: 50/50RH

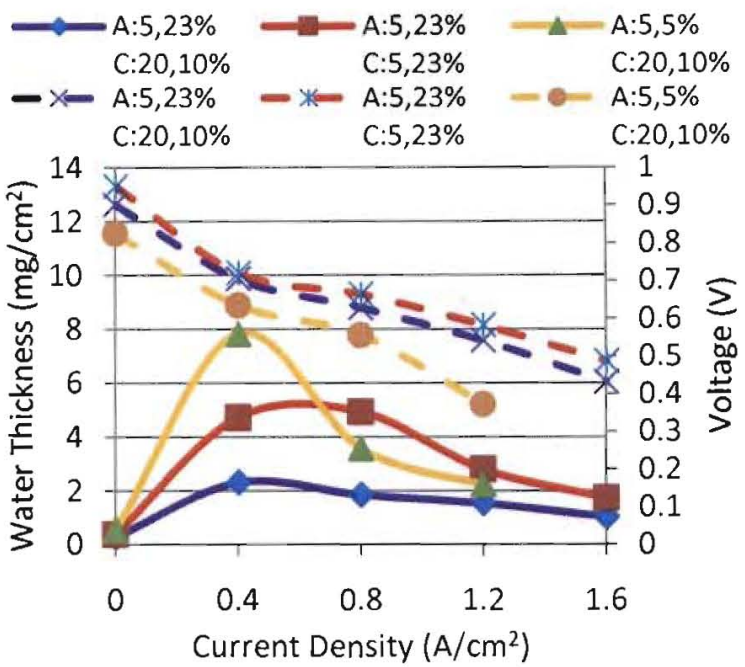

Figure 1: Comparison of water in the land area (left) and channel area (right) among single-serpentine channel fuel cells operating at 50\%/50\% inlet RH.

All cells show there is little water at low current densities, and that the maximum water content is at medium current densities, between 0.4 and $0.8 \mathrm{~A} / \mathrm{cm}^{2}$. At higher current densities higher volume flow rates and/or the heat generated are more effective at removing liquid water from the channels. This agrees with prior neutron imaging studies (15).

In comparison to cell 1 , cell 4 has a change in PTFE loading in the anode-side GDL and MPL, and cell 2 has a change in the PTFE loading on the cathode-side GDL and MPL. A large impact is made on both performance and water content by increasing the PTFE loading in the MPL on the anode side from $5 \%$ (orange circles) to $23 \%$ (blue diamonds). The performance increased at all current densities, and there is less water in both the channel and land. When the MPL is not very hydrophobic, water is driven to the anode side and accumulates more. The decrease in the water under the lands is not as significant.

The second comparison, between cells 1 and 2, is a change in PTFE loading on the cathode side from 5\% substrate and 23\% MPL (red) to $20 \%$ substrate and 10\% MPL (blue). The 20\%/10\% GDL/MPL had higher performance and also had higher water content. This result is consistent with previous high resolution cross-section imaging performed on fuel cells that indicate that low Teflon loading in the GDL substrate can lead to significant water accumulation without affecting the performance (16).

Similar comparisons can be made for the three single-serpentine cells operating at $100 \% / 100 \%$ RH, as shown in Figure 2 below. Although, not all the same operating conditions were tested. There is an increase in water content at the higher RH. At 0 $\mathrm{A} / \mathrm{cm}^{2}$ there is still water, indicating that the saturated flows are unable to remove water and residual water exists. 
Land: $100 / 100 \mathrm{RH}$

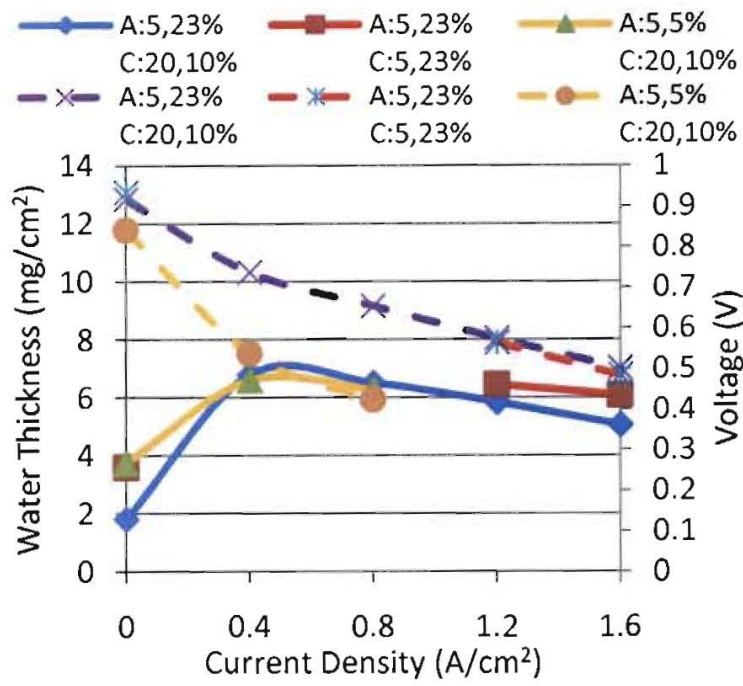

Channel: $100 / 100 \mathrm{RH}$

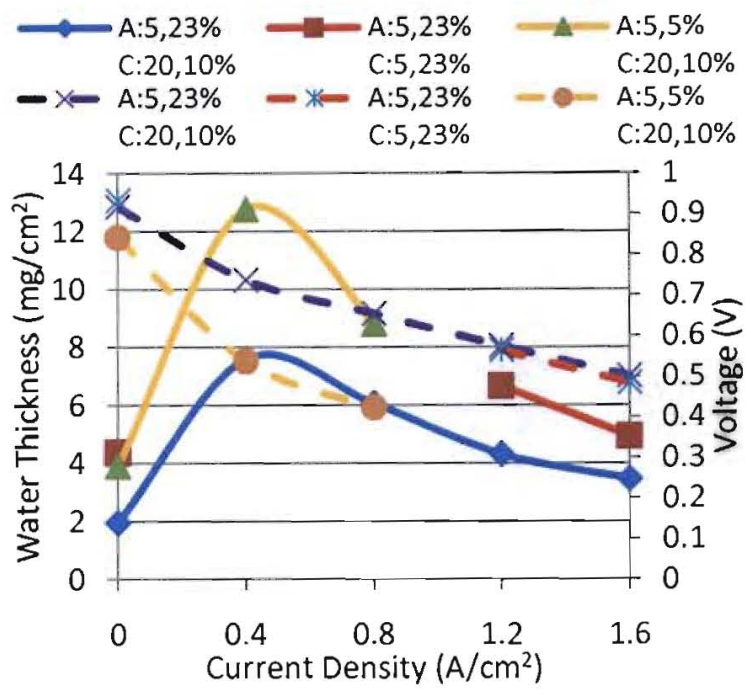

Figure 2: Comparison of water in the land area (left) and channel area (right) among single-serpentine channel fuel cells operating at $100 \% / 100 \% \mathrm{RH}$.

\section{Single vs Quad Serpentine Flow Fields}

Comparisons of cells 1 and 5, which have the same PTFE loading for different flowfield geometry, are shown below in Figure 3.
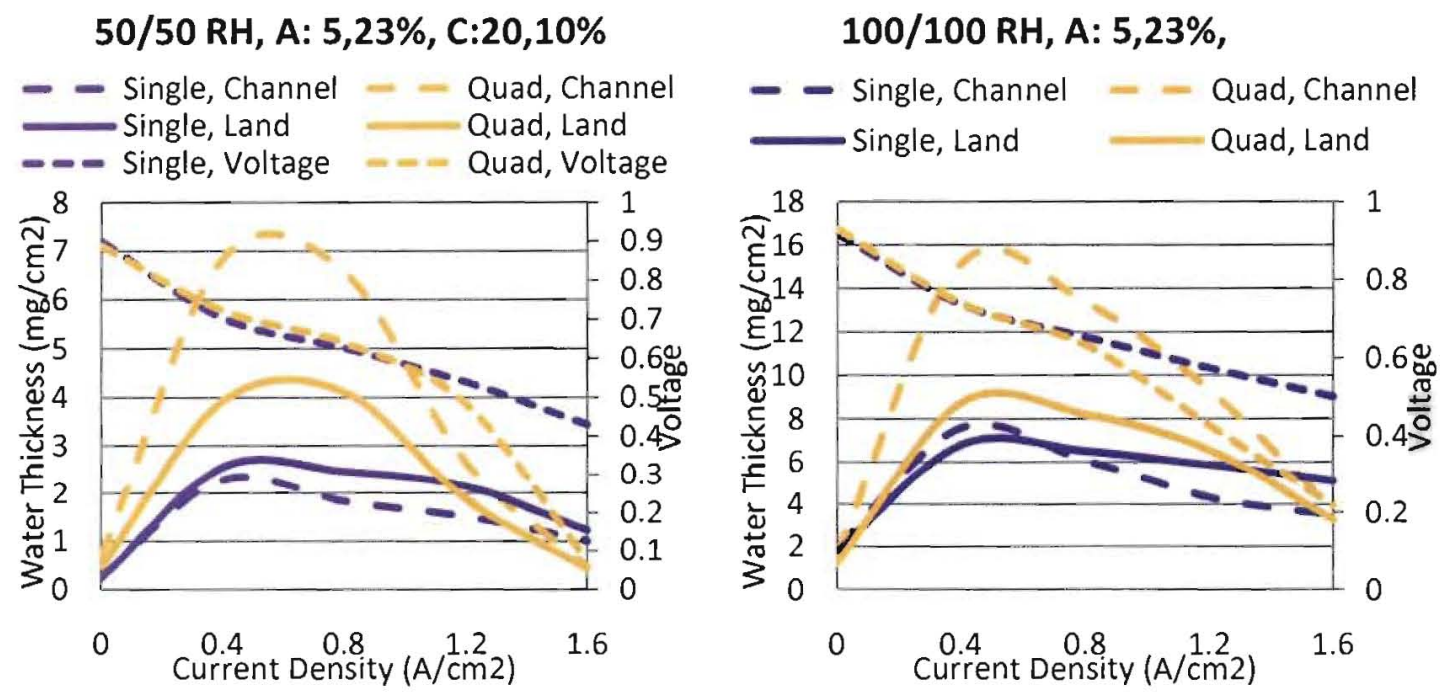

Figure 3: Comparison of water content between single and quad serpentine cells

The quad serpentine cell exhibits higher water content than the single serpentine cell except at the highest current density. There was also a reversal of the channel/land trend from the single-serpentine case, in that the quad-serpentine case had more water under the channels than under the lands. Along each path from inlet to outlet there are fewer $180^{\circ}$ turns for a quad-serpentine flow field than for the single-serpentine flow field, which results in a lower pressure drop, and lower flow velocities within each channel. This decreases the water removal abilities of the fuel cell, leaving much higher channel water content. Due to there being multiple paths through the flow field, if there are liquid 
water droplets in one of two of the serpentine paths, the flow can redirect preferentially through one of the other serpentine paths.

\section{Along-channel water distribution}

Wood used segmented cells to show the performance (12) along the channel for different GDLs. This can be compared to the water content found in this study.

The colorized neutron images of the water content for cells 1 and 2 are shown in the left and center part of Figure 4, and they were segmented according to the diagram shown on the right part of Figure 4, and additionally broken into channel and lands. The water evolution along the channel and lands is shown in Figure 5.

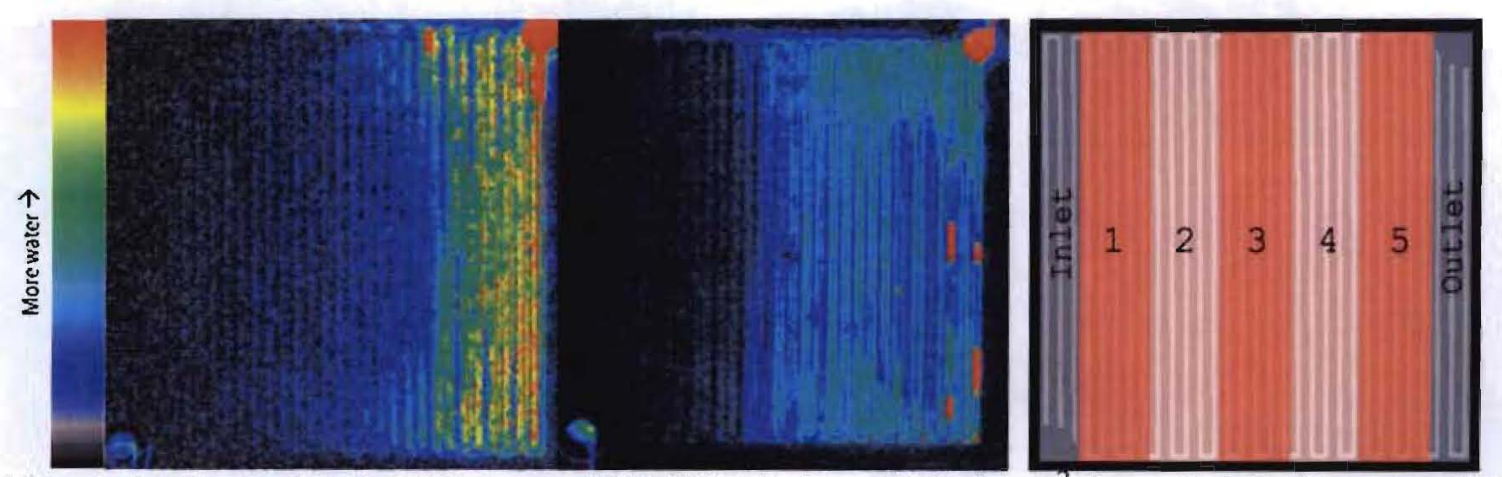

Figure 4: Water density images at $50 \% / 50 \% \mathrm{RH}$ and $0.8 \mathrm{~A} / \mathrm{cm}^{2}$ for cell 1 (left) and cell 4 (center), and segments for single-serpentine channel (right).

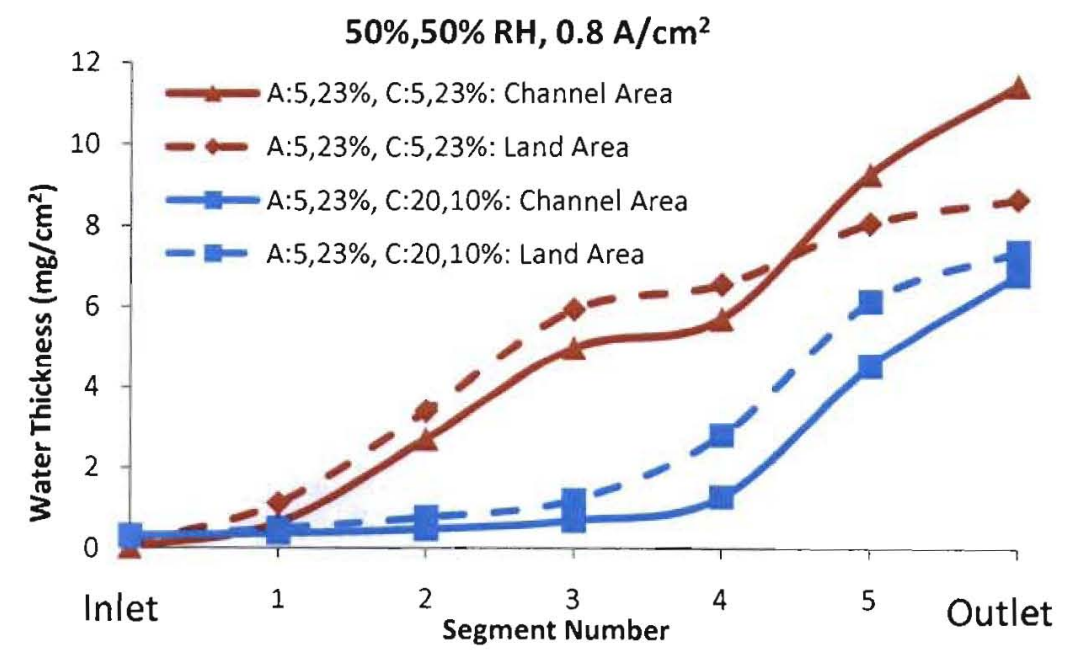

Figure 5: Water evolution along the channel for cells 1 and 2.

The previous section showed that there is higher water content overall for cell 2 (red). When looking at the segments, it can be seen that the water begins to accumulate much earlier than in cell 1. The performance data in Ref. (12) showed higher performance for the last segment of the fuel cell, and also showed that the BC 5,23\% PTFE GDL outperformed the DI 20,10\% PTFE. Figure 5 shows that the liquid water onsets earlier and the cell has more water content through the flow-field length. At dry gas flows, 
thethe higher PTFE content of the MPL helps to keep the membrane hydrated without leading to mass transport limitations.

\section{Conclusions}

This study examines the water content in four PEM fuel cells using various combinations of SGL Carbon GDLs with different PTFE loadings for steady state operation at different relative humidities, various current densities and two types of serpentine flow fields. In-situ neutron imaging was used to determine the liquid water content inside fuel cell during operation. The effect of various GDL properties on the water content and fuel cell performance was presented and discussed. Higher PTFE loading in the MPL of the anode-side GDL was shown to decrease the water content under both the channel and lands, while also increasing the fuel cell performance. A more hydrophobic MPL can prevent water from accumulating on the anode side. Decreased cathode GDL substrate PTFE in association with increased MPL PTFE impedes water loss from the PEM at low humidity, which helps to increase performance.

\section{Acknowledgments}

This work was supported by the U.S. Department of Energy (DOE) Fuel Cell Technologies (Technology Development Manager: Nancy Garland). This work was also supported by the U.S. Department of Commerce, the NIST Ionizing Radiation Division, the Director's Office of NIST, the NIST Center for Neutron Research, and the Department of Energy through interagency agreement no. DE-AI01-01EE50660. We also thank Peter Wilde of SGL Group for providing the GDL materials.

\section{References}

1. C.-Y. Wang, Chemical Reviews, 104, 4727 (2004).

2. Y. Wang, Journal of Power Sources, 185, 261 (2008).

3. Y. Wang, C. Y. Wang and K. S. Chen, Electrochimica Acta, 52, 3965 (2007).

4. U. Pasaogullari, C.-Y. Wang and K. S. Chen, Journal of The Electrochemical Society, 152, A1574 (2005).

5. A. Z. Weber, R. M. Darling and J. Newman, Journal of The Electrochemical Society, 151, A1715 (2004).

6. A. Z. Weber and J. Newman, Journal of The Electrochemical Society, 152, A677 (2005).

7. L. Giorgi, E. Antolini, A. Pozio and E. Passalacqua, Electrochimica Acta, 43, 3675 (1998).

8. V. A. Paganin, E. A. Ticianelli and E. R. Gonzalez, Journal of Applied Electrochemistry, 26, 297 (1996).

9. F. Lufrano, E. Passalacqua, G. Squadrito, A. Patti and L. Giorgi, Journal of Applied Electrochemistry, 29, 445 (1999).

10. E. Antolini, R. R. Passos and E. A. Ticianelli, Journal of Applied Electrochemistry, 32, 383 (2002).

11. S. Park, J.-W. Lee and B. N. Popov, Journal of Power Sources, 177, 457 (2008).

12. D. L. Wood, R. Mukundan and R. Borup, ECS Transactions, 25, 1495 (2009).

13. J. R. Davey, R. Mukundan, J. S. Spendelow, P. P. Mukherjee, D. S. Hussey, D. L. Jacobson, M. Arif and R. Borup, ECS Transactions, 25, 971 (2009). 
14. M. A. Hickner, N. P. Siegel, K. S. Chen, D. N. McBrayer, D. S. Hussey, D. L. Jacobson and M. Arif, Journal of The Electrochemical Society, 153, A902 (2006).

15. T. A. Trabold, J. P. Owejan, D. L. Jacobson, M. Arif and P. R. Huffman, International Journal of Heat and Mass Transfer, 49, 4712 (2006).

16. P. P. Mukherjee, R. Mukundan, J. S. Spendelow, J. R. Davey, R. Borup, D. S. Hussey, D. L. Jacobson and M. Arif, ECS Transactions, 25, 505 (2009). 